\title{
The Integration of Dynamic Assessment in L2 Classroom: How Students Perceive it?
}

\author{
WidyaRatna Kusumaningrum ${ }^{1}$ \\ ${ }^{1}$ Tidar University \\ ${ }^{1}$ kusumaningrum@untidar.ac.id \\ C. Prima Ferri Karma ${ }^{2}$ \\ ${ }^{2}$ Tidar University \\ ²ferriprima1@gmail.com
}

\begin{abstract}
The present study focuses on the implementation of a traditional diagnostic test for speaking skill in the form of an interview with no specific set of corrective procedure. However, it triggers more increasing worries on the significance of standardized test such as not being able to unlock students' speaking potential. This study highlights on Dynamic Assessment (DA) based on the Vygotsky's Sociocultural Theory (1978). Fundamentally, DA inserts mediation process such as prompts, hints, and leading questions in its interview process. This study compares the efficacy of Dynamic Assessment (DA) and the standardized diagnostic test/Non-Dynamic Assessment (NDA) in diagnosing and unlocking their potential. Using quasiexperimental research with non-equivalent group design (NEGD), this study focused on four micro speaking skills including pronunciation, vocabulary, grammar, and fluency. The results suggested that the use of DA was able to identify their current speaking performance and uncover their speaking potential even if some were claimed to have a similar speaking level. While the standardized test (NDA) emphasized only on the current performance and was not able to elicit their potential.
\end{abstract}

ARTICLE HISTORY

Received 19 September 2018

Accepted25 October 2018

\section{KEYWORDS}

Standardized test; assessment

\section{Introduction}

The changing direction of effective instruction has resulted in the shifting paradigm from the notion of 'assessment of learning' to 'assessment for learning.' Its primer function makes a test has potentially become polemic and controversial both for teachers and students. For long, the term assessment was identified and used to estimate the efficacy and impact of the complete teaching and learning process (William, 2011). It results in the negative stereotype of a test. Students often dislike it and connote it with a score, competition, pain, and fear (Nimehchisalem, \& Mat Hussin, 2018).

As the inseparable part of an instructional process, assessment should be aimed to help the activation both learners' cognitive and metacognitive processes (Ableeva\&Lantolf 2011; Tzuriel 2011). With these principles, assessment functions 
to diagnose the students' level and to identify their strengths and weaknesses to promote successful language learning (Kellough\&Kellough, 1999). At this point, it suggests the integration of Dynamic Assessment (DA) in the L2 Classroom.

Emerged from the work of Vygotsky (1978) with the Sociocultural Theory and Feuerstein \& Hoffman (1979) with the Structural Cognitive Modifiability, DA has raised attention and awareness of the educational practitioners to adopt such concept. DA offers learners' cognitive development within meditation and social interaction given by more competent individuals such as teachers or peers (Kinginger, 2002). In other words, DA is no longer seen as an assessment method or instrument but rather the framework of the integration of teaching and assessment to understand the learner talents and to support their development (Poehner, 2008). Since then DA procedure has been widely studied using varied research methods. Some recent works offer engaging discussion about the integration of DA in L2 classroom (Hessamy\&Ghaderi, 2014; Shrestha\& Coffin, 2012; Ableeva, 2008; Hidri, 2014; Lantolf\&Poehner, 2011).

Hessamy\&Ghaderi (2014) investigated the role of DA to promote EFL learners' vocabulary learning. They attempted to understand the statistical differences between the DA group and non-DA group using an experimental design. The participants involved in their study were Iranian students $(\mathrm{N}=50)$ with the intermediate level of English and within 13-16 years old. The participants were then divided into two groups of experimental group and control group. The DA used in this study was the sandwich model of DA (pretest-mediation-posttest). The statistical data were analyzed using ANCOVA, and it showed that the DA group as the experimental group outperformed the NDA (the control group).

Shrestha\& Coffin (2012) explored the significance of tutor mediation and distance learning in developing learners' academic writing. This study integrated the DA and distance learning. Investigated under qualitative research design, this study explored the higher education level students' point of view on how the integration of DA and distance learning contribute their academic writing development to respond to their individual needs. The findings suggested that the meditational moves given helped the students in developing their writing abilities as well as widened their ZPDs as shown from the quantity and quality of the support provided.

Hidri (2014) addressed his study to develop and evaluate the listening comprehension test for EFL learners by adopting Dynamic Approaches. This study included 60 Tunisian EFL Learners and 11 raters. The participants were involved in the two listening comprehension models (traditional and Dynamic approach). This study was investigated under quantitative with Multi-Facet Rasch Measurement (MFRM) (FACETS program, version, 3.61.0) and qualitative to detect the learners' cognitive and meta-cognitive processes at its research design. The results suggested that DA might help the raters and documents the participants' cognitive level and 
meta-cognitive levels better than the traditional approaches. Thus, this study concluded that DA gave positive implications for the listening assessment practices.

Lantolf\&Poehner (2011) reported how a Spanish elementary school teacher interacted with her students using the DA principles in her teaching practice. In this study, they observed the teacher's daily activity and practices by using the qualitative research design. They detailed the analysis of the teacher-student interaction and documented all the observational behaviors such as the facial expression, intonation, and other indicators. They concluded that this non-experimental research might open the opportunities for seeing the learner's development.

Many studies on DA review and detail the impact of DA as one of the approaches in assessment for learning. Mostly these studies used quantitative research design, statistical data, and quantification, but still few studies used the qualitative descriptive research focusing on the learners' perspectives. Thus, the study tries to investigate the students' voices towards the integration of Dynamic Assessment in EFL Classroom, with the research question, as follow:

RQ 1. What are the shared views of the EFL learners toward the integration of dynamic assessment in L2 classroom?

\section{Methodology}

\section{a. Research Design}

The current study attempted to investigate the voices of EFL learners and teacher toward the integration of dynamic assessment in the L2 classroom. To answer the aforementioned research question, this study used a descriptive qualitative research design. It portrayed and gave the depiction on how these students express their voices about DA.

\section{b. Participants}

This study involved 40 respondents with the age range from 14-15. They were junior EFL students of a public school in Central Java, Indonesia. They were chosen since they were treated the DA from the preliminary study in a few months, which made them familiar with the procedure given.

\section{c. Instruments}

To see what is happening and collecting such information, this study involved open-ended questionnaire. The questionnaire used the open-ended model. The questionnaire was an open-ended questionnaire, which let the participants answer honestly. The survey took 20-25 minutes to complete. It had seven questions focusing on motivation, anxiety, mental and physical conditions, need, engagement, confidence, awareness, and self-reflection (Karimi and Shafiee, 2014).

\section{d. Procedure}


The study was the continuation of the preliminary research investigating the effect of DA principles with a pretest-posttest design. After six meetings of the quantitative study, we would like to have the students' voices and point of views about the implementation of DA in their classroom by using the questionnaire as mentioned above. The raw data from the questionnaire were used as the main data, which then were analyzed using the following techniques of data analysis.

\section{e. Data Analysis}

To analyze the data, the study adopted the Miles, Huberman and Saldana' data analysis technique (2014). It included data collection, data display, data reduction, and conclusion drawing and verification. The raw data taken from the questionnaire were collected from all of the respondents who had been treated and familiar with the procedure or stages of Dynamic Assessment. All of the data were then displayed and categorized based on the aspects mentioned above such as (1) procedure, (2) learners' engagement, and (3) learners' motivation. The data were then classified into two types: selected and unselected data. Lastly, the selected data were analyzed to draw the conclusion and proper verification.

\section{Results and Discussion}

In the present study, the results were presented and studied to get the in-depth comprehension and discussion. All of the data were taken from the questionnaire, which was conducted in Indonesian and translated into English. Those were depicted in seven major classifications, as follows.

Table 1. Participant perception by category

\begin{tabular}{lc}
\hline \multicolumn{1}{c}{ Category } & Total \\
\hline Learners' motivation enhanced during the assessment process & $67.50 \%$ \\
\hline $\begin{array}{l}\text { Learners' anxiety which impedes the assessment process could be } \\
\text { minimized }\end{array}$ & $72.50 \%$ \\
\hline $\begin{array}{l}\text { Mental and physical conditions of learners would affect their } \\
\text { performance during the assessment process }\end{array}$ & $70.00 \%$ \\
\hline $\begin{array}{l}\text { Individual differences among learners necessitated the constant and } \\
\text { varied teachers' feedbacks to enhance learning process continuously } \\
\text { and dynamically }\end{array}$ & $75.00 \%$ \\
\hline $\begin{array}{l}\text { Engagement of learners in tasks helps assess their learning progress } \\
\text { dynamically }\end{array}$ & $70.00 \%$ \\
\hline $\begin{array}{l}\text { Learners' confidence for self-expression was facilitated during the } \\
\text { assessment process }\end{array}$ & $70.00 \%$ \\
\hline $\begin{array}{l}\text { Self-reflection and critical thinking were encouraged during the } \\
\text { process }\end{array}$ & $75.00 \%$ \\
\hline
\end{tabular}

a. The enhancement of learners' motivation 
In this section, the study focused on the implementation of the procedure such as the assistance and the implicit-explicit prompts given. The assistance given during the process had an impact on their learning motivation and was seen positively by $67.5 \%$ of the number of respondents. Twenty-seven students agreed that the procedure they had during the assessment process had elicited their motivation improved for further learning. Once the external motivation affects the internal motivation, it means that the students may initiate the individual learning consistently.

Data 1: It was the first time for me to have such an assessment procedure. It was exciting and somehow motivated me to know my problems and my learning. (P3)

Data 2: It was different from the speaking test I had. I liked it, and it has attracted my attention to learning more. (P7)

Data 3: Although it has been done within 5 activities, I love the assessment procedure. I was assessed but I know the correct form, and it made me study more and not to make a similar mistake. (P11)

Further investigated, the DA procedures, which assisted to understand the current personal level contributed to the increases in learning motivation. The participants had a similar reason for that.

Data 4: What I like about the assessment was I knew my level. For example, when I found it hard to utter the sentences with correct past form, I kept guessing it until I predicted the correct one. Even it took some time, I knew my current level, and I would improve to have a better level by remembering the mistake that I had. (P27)

Data 5: Outside of the classroom, I asked my friends who had a similar mistake in the beginning. What made me happy was that we were identified as having a different current level not just as simple as generalizing us to have the same level. (P33)

\section{b. The Learners' Anxiety}

Learners' anxiety is seen as the distinct affective variables and feature of learners' perceptions and behaviors affecting the language learning process. These variables were associated with the negative attitudes indicated by muscle tension, stress, fright, and nervousness. These may impede us from the learning. The implementation of DA as the alternative assessment has reduced the learners' anxiety they experienced during the static and traditional assessment and created the warm teaching atmosphere.

Data 6: The assessment model was different from the usual model. We sat one by one instead of performing our speaking in front of the class. As we got the assessment process, we never felt that we had the assessment process. We 
only did the tasks such as narrating the story, but once we had problems, the teacher kept asking until we were able to find our answers. (P1)

Data 7: It was so much fun. We never realized that we were being assessed since the procedure let us sit in the chair and discussed the correct answer the teachers. (P13)

Data 8: I was happy since I wasn't as nervous as before. We have assessed our speaking competence, but at the same time, we learned something. (P23)

Data 9: It was the first time for me not feeling that nervous during the speaking test. We had some procedure such as describing the picture, retelling the story and reading aloud text. Since we only sat together and had a particular intervention, we felt good about it. (P35)

Twenty-nine students or $72.50 \%$ had a common assumption towards the intervention in the DA procedure that it had helped the learners' to lessen their nervous level. The mediation varied from one individual to others and had been able to reduce the academic pressures they had.

\section{c. The mental and physical conditions}

The mental condition was associated with the intellectual and affective properties such as ideas, critical thinking, creative thinking, and readiness, while the physical condition is related to health, physical development, nutrition, and other physical deficiencies. These both mental and physical conditions affect the students' readiness in language learning and testing. Students might lose their interest and concentration during the test time. During the implementation of the DA, learners' mental and physical conditions were little affected by the procedures and the treatment given. 28 students or $70 \%$ of the participants shared the same arguments and point of view that their physical and mental conditions were less affected during the DA procedure than the previous test, as illustrated below:

Data 10: During a speaking test, it was easy for me to have any severe mental and physical conditions, and it made me nervous and could not think any right answers. However, since the procedures and the assistance given during the DA test, I felt better and relaxed. (P14)

Data 11: Hearing the term assessment or test has made my mental and physical conditions terrible. I usually was sweating like a pig. I had never been able to show my best performance. I felt stressful and so forth. The intervention given during the tests by adding some jokes here and there made the test was like a regular conversation. (P29)

As these two mentioned excerpts, mental and physical conditions of learners would affect their performance during the assessment process, Interchangeably, the type of tests might affect their mental and physical conditions. In this context, the students would be benefitted if their psychological and physical conditions were not affected by the tests. 


\section{d. The individual feedbacks}

The individual differences among learners necessitated various and constant feedbacks to see their different competence level. The feedbacks were necessary not only to understand their present performance but also to enhance their learning. This characteristic becomes the fundamental principle distinguishing the DA as the alternative assessment of the old traditional paradigm. Instead of giving direct verbal feedback, each participant experienced the self-regulatory indicating the directness level of feedback. Each was accommodated the indirect to direct wash back.

Data 12: What I like about the procedure was related to the feedbacks given. Some of us might mispronounce the word 'disturb' but after some prompts and feedbacks, we know the correct answer. (P25)

Data 13: DA was such a unique procedure, in which we were tests and every mistake that we faced the intervention was started. The interviewer kept asking the correct answer and asked us to try to respond. We had to think first before we gave up to answer. It might be taking so much time, but the procedure had a positive impact toward the vocabulary acquisition. We might remember it well. (P39)

Thirty participants or $75 \%$ expressed the typical point of view by stating they were benefitted from the procedure.

\section{e. The Learner Engagement}

To build a good assessment atmosphere, the participants should raise their awareness of the importance of the assessment for their further learning. The participants should be engaged in doing the activity to help the assessment process done dynamically and progressively. The excellent quality of the prompts and feedbacks were opted to foster their engagement. 28 out of 40 participants said that they were actively involved in the DA procedure.

Data 14: I would say that the test procedure made me actively participated. I was asked to keep guessing the correct answer, and the teacher would not let me know the right answer. Once I understood the procedure, I made sure myself not making the same mistakes and it made the fitting conclusion given for my ability. (P18)

Data 15: I think the level of engagement during this test would be the feeling of not being tested. At first, I felt nervous, but later I forgot that I was being tested. (P34)

From the two excerpts above, it was clear that the learners were engaged and they assumed that the DA procedure was not as frightening and intimidating as they might think before. 


\section{f. The Learners' Confidence}

It was essential for us to comprehend the relation between the learners' confidence during the assessment process. Even there were some pros and cons that assessment would judge an individual from the surface level, we had to understand that a proper assessment procedure would benefit them since it documented their confidence and best performance. The similar students would agree that DA procedure engaged them, they claimed that it would nurture their confidence.

Data 16: Once I was engaged with the procedure, I had the confidence to do the task well. (P22)

Data 17: In my opinion, the activity would improve our confidence, not to mention, we never felt that we were being tested. (P34)

\section{g. Self-Reflection and Critical Thinking}

The last aspect that characterized the principles of DA was the involvement of self-reflection and the improvement of critical thinking. During the process, all of the participants would reflect their answers from the given hints and stimulus. They might not be allowed only to stop and ask for the correct answer. They had to think all possible answers came up to their mind.

Data 18: It was hard to guess the exact answer. Once we stop the teacher gave us some minutes to think the correct answers. I was encouraged to predict the right answer. (P25)

Data 19: I would think that it was a good assessment procedure in which it helped us to build our critical thinking. (P40).

From the results, it might be assumed that most of the students had positive attitudes and views towards the DA procedure. They consider that DA procedure as the alternative assessment. Despite the strength, DA has challenges that limited the practice would be presented, as follows.

Table 2. Challenges by category

\begin{tabular}{cl}
\hline No & \multicolumn{1}{c}{ Challenges } \\
\hline 1 & The time constraint \\
\hline 2 & There was more waiting line \\
\hline 3 & Students found it difficult in understanding the prompts \\
\hline
\end{tabular}

One of the most critical constraints was the time for each session. Three interviewers did the DA procedure in the class. During the 90-minute session, the students involved were limited. We had to give them another task for them while waiting for their turns. Further investigated for evaluating all of the students it took at least three sessions. It was not useful to do such activity. Not to mention, some of them might have difficulty in understanding the hits or stimulus given. It might take 
some minutes to wait them answer correctly particularly the procedure let us discuss the answer to help their future learning.

\section{Conclusion}

The findings of the study provide support for the implementation of DA.Ittestified variation views and perceptions expressed by some junior high school students toward the integration of Dynamic Assessment as the alternative assessment measuring the speaking skills. The students perceive DA as a positive procedure over the negative challenges they face. They assumed that the procedural steps of DA built the self-reflection, critical thinking, motivation, engagement, and confidence as well as lessen their mental and physical conditions and anxiety. The application of DA helped not only the teachers but also the students themselves to know their capacity in learning. Despite the strength, DA has a limitation predominantly dealing with time, in which for evaluating all of the students it took at least three sessions. These challenges may become further research for other researchers. 


\section{References}

Ableeva, Rumia. 2008. "The Effects of Dynamic Assessment on L2 Listening". In Sociocultural Theory and the Teaching of Second Languages edited by Lantolf, James P. and Poehner, Matthew E., 57-86. London: Equinox.

Ableeva, Rumia, \&Lantolf, Jim. 2011. "Mediated Dialogue and the Microgenesis of Second Language Listening Comprehension." Assessment in Education 18, No.2: 133-149. https://doi.org/10.1080/0969594X.2011.555330

Feuerstein, Reuven, Rand, Ya'acov, \& Hoffman, Mildred. B. 1979. The Dynamic Assessment of Retarded Performers. Baltimore, MD: University Park Press.

Hessamy, Gholamreza, and Ghaderi, Esmaeil. 2014. "The Role of Dynamic Assessment in the Vocabulary Learning of Iranian EFL Learners." ProcediaSocial and Behavioral Sciences 98: 645-652. https://doi.org/10.1016/j.sbspro.2014.03.463

Hidri, Sahbi. 2014. "Developing and Evaluating a Dynamic Assessment of Listening Comprehension in an EFL Context." Language Testing in Asia 4, No.4: 1-19 https://doi.org/10.1186/2229-0443-4-4

Karimi, Mohammad Nabi, \&Shafiee, Zahra. 2014. "Iranian EFL Teachers' Perceptions of Dynamic Assessment: Exploring the Role of Education and Length of Service." Australian Journal of Teacher Education 39, No.8: 143162. https://doi.org/10.14221/ajte.2014v39n8.10

Kellough, Richard D., \&Kellough, Noreen. G. 1999. Secondary School Teaching: A Guide to Method and Resources Planning for Competence. Upper Saddle River, New Jersey: Prentice Hall.

Kinginger, Celeste. 2002. "Defining the Zone of Proximal Development in US Foreign Language Education." Applied Linguistics 23, No.2: 240261.https://doi.org/10.1093/applin/23.2.240

Lantolf, James P., and Poehner, Matthew E. 2011. "Dynamic Assessment in the Classroom: Vygotskian Praxis for L2 Development". Language TeachingResearch15, No.1: 11-33. https://doi.org/10.1177/1362168810383328

Miles, Matthew B., Huberman, A. Michael, and Saldana, Johnny. 2014. Qualitative Data Analysis: A Methods Sourcebook and The Coding Manual for Qualitative 
Researchers. California, USA: SAGE.

Nimehchisalem, Vahidand Mat Hussin, NurIzyanSyamimi. 2018. "Postgraduate Students' Conception of Language Assessment." Language Testing in Asia 8, No.11: 1-14. https://doi.org/10.1186/s40468-018-0066-3.

Poehner, Matthew .E. 2008. Dynamic Assessment: A Vygotskian Approach to Understanding and Promoting L2 Development. University Park, PA: Springer.

Shrestha, Prithvi. \& Coffin, Caroline. 2012. "Dynamic Assessment, Tutor Mediation, and Academic Writing Development." Assessing Writing 17, No.1: 5570.https://doi.org/10.1016/j.asw.2011.11.003

Tzuriel, David. 2011. "Mediated learning and cognitive modifiability." In Encyclopedia of Sciences of Learning edited by N.M. Seel, 2154-2157. New York, USA: Springer Publishing.

William, Dylan. 2011. "What is Assessment for Learning? "Studies in Educational Evaluation 37, No.1:3-14.https://doi.org/10.1016/j.stueduc.2011.03.001

Vygotsky, Lev Semyonovich. 1978. Mind in society: The development of higher psychological processes. Cambridge, MA: Harvard University Press. 